
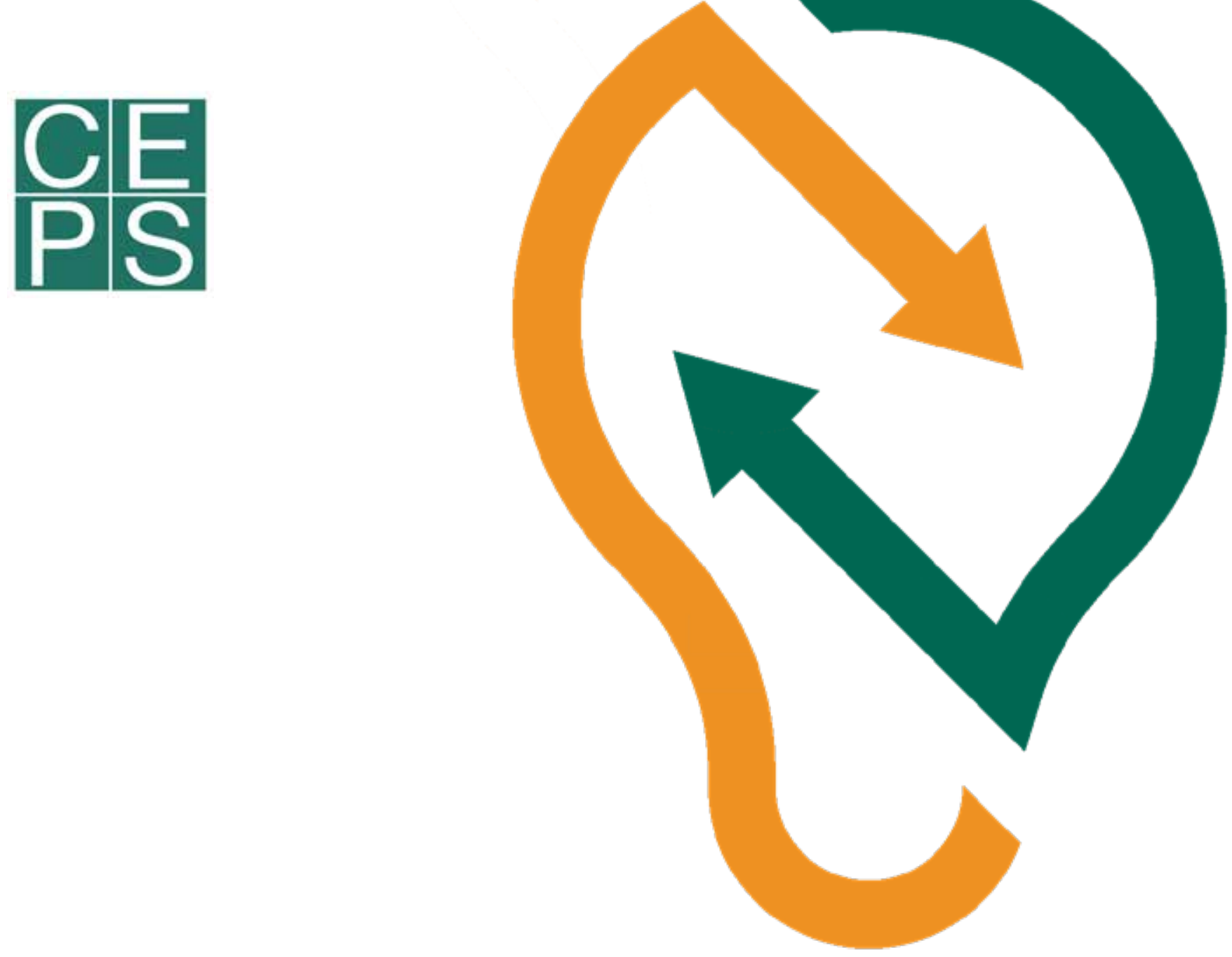

\title{
RECOVERY AND RESILIENCE
}

\section{REFLECTION PAPERS}

Jorge Núñez Ferrer

CEPS Associate Senior Research Fellow
№. 1 | March 2021

AVOIDING THE MAIN RISKS IN THE RECOVERY PLANS OF MEMBER STATES 


\title{
Q \\ RECOVERY and RESILIENCE REFLECTION PAPERS \\ Avoiding the Main Risks in the Recovery Plans of Member States
}

\author{
Jorge Núñez Ferrer
}

This is the first of a series of reports dedicated to the preparation and implementation of the Recovery and Resilience Facility of the EU. It sets out some of the main risks to the success of the recovery programmes, such as a lack of focus and mistargeting, maintaining unsustainable sectors, delays in implementation, and the lack of both a European dimension and the capacity to implement such a complex programme over and above the normal EU budget.

These risks can be mitigated or avoided, however. The report also presents a number of solutions to ensure that aspects critical to the recovery programmes - and the key objective of longer-term resilience - are implemented. It highlights the necessity for serious structural reforms in member states, better management and control systems at EU level, well-designed active labour market policies, and a clear framework for public private partnerships to ensure that they are used more effectively.

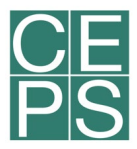

Jorge Nunez Ferrer is Associate Senior Research Fellow at CEPS

This report is the first in a series of regular outputs of a research programme on the preparation and implementation of the Recovery and Resilience Facility of the EU, which has been discussed and reviewed by the members of a Recovery and Resilience Reflection Group.

Group members participate monthly in a short discussion and submit comments on the draft reports. The contents convey the results of the research and members' comments, but the recommendations do not necessarily reflect a common position reached by all members, nor do they represent the views of the institutions to which the members belong.

The author also would like to thank his colleagues, Cinzia Alcidi and Francesco Corti for the comments and support and Jackie West and Margarita Minkova for their editorial and design support. A list of the reflection group members appears in the annex to this report. Image credit: Vecteezy.com

CEPS is an independent think tank based in Brussels. Its mission is to produce sound policy research leading to constructive solutions to the challenges facing Europe today. 


\section{Contents}

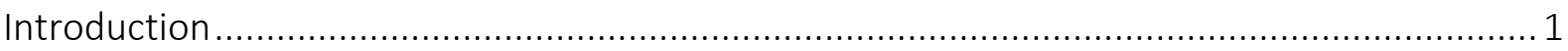

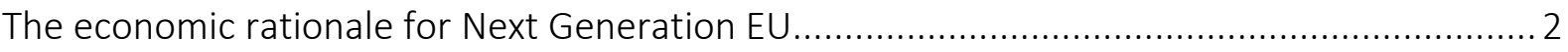

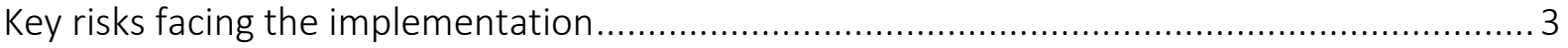

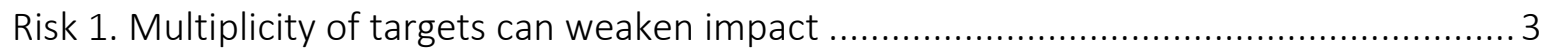

Risk 2. Sustaining imbalances in the economy through subsidies ................................... 4

Risk 3. Delays in starting the recovery programme ......................................................... 5

Risk 4. Lack of European dimension in an integrated economy …................................ 6

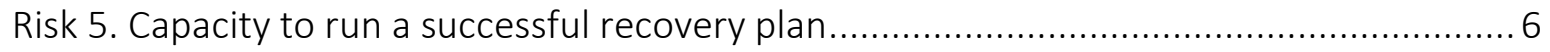

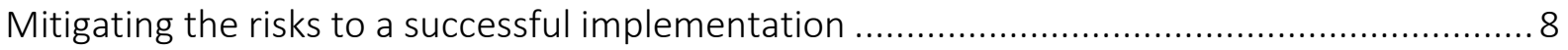

Solution 1. National reforms are a pillar to recovery ...................................................... 8

Solution 2. EU reforms to improve implementation effectiveness and speed ..................... 8

Solution 3. Active and useful labour market policies..................................................... 9

Solution 4. Enhancing and improving the use of public private partnerships .................... 10

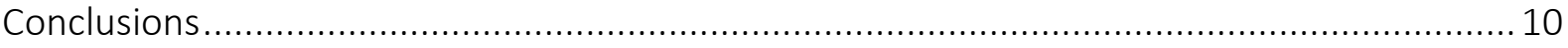

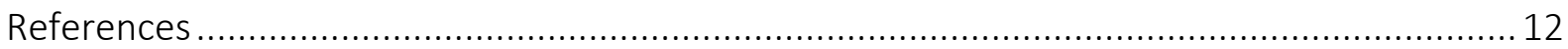

Annex 1. Members of the Recovery and Resilience Reflection Group ................................. 13 


\section{Introduction}

Member states are drawing up their plans for the use of the Recovery and Resilience Facility (RRF) of the Next Generation EU (NGEU). This support instrument comes on top of the EU multiannual financial framework of the EU budget. Only a limited part of the funds will be managed by applying the same rules as for the EU budget funds, namely those allocated to the specific headings of the budget. For the largest amount, the rules to follow are presented in the regulation for Recovery and resilience facility ${ }^{1}$ and the guidelines produced by the European Commission. ${ }^{2}$

In the final composition of the NGEU, the overwhelming share of the funding goes to the RRF, namley $€ 672$ bn (of which grants are $€ 312.5 \mathrm{bn}$ and loans $€ 360 \mathrm{bn}$ ). There is a $€ 47.5$ bn increase for Cohesion Policy (ReactEU); $€ 5$ bn in grants for research and innovation, funding for debt and equity in the InvestEU financial instruments; $€ 7.5 \mathrm{bn}$ for rural development; $€ 10$ bn for the Just Transition Fund, and $€ 1.9$ bn for the Union's civil protection mechanism.

The adoption of the RRF national programmes will not take place until the spring of 2021 at the earliest, but it is not the only support instrument in place. Several other EU and national support instruments have been deployed to cushion the immediate effects of the pandemic, while the multiannual financial framework (MFF) for 2014-20 programmes continue in their implementation, as considerable amounts are committed from 2021 to 2023.

The Corona Response Investment Initiative (CRII) is also being deployed until mid-2021. Programmes such as ReactEU of the NGEU already entered into force and are being implemented. ${ }^{3}$ National measures will continue to play a role. The RRF should not be seen as a measure to further cushion the impact of the pandemic, but to redirect and reinforce the economy.

This paper lists some of the most important aspects to consider when implementing the NGEU (especially the RRF), and which need special attention when evaluating the national programmes. It will first present the basic economic rationale of the RRF then move on to the risks and solutions to remove implementation barriers and mitigate the negative impacts of the crisis. Five main risks are presented that could negatively affect the recovery process, as well as four solutions to avoid those risks becoming a reality. ${ }^{4}$

NGEU is an important opportunity for the EU to move in the right direction and face multiple challenges, but the balance between the multiple objectives is hard to strike. It is also fraught

\footnotetext{
${ }^{1}$ Regulation 2021/241establishing the Recovery and Resilience Facility, 12 February 2021

2 All guidelines are published at https://ec.europa.eu/info/business-economy-euro/recovery-coronavirus/ recovery-and-resilience-facility en.

3 Regulation 2020/2221 amending Regulation (EU) No 1303/2013 as regards additional resources and implementing arrangements to provide assistance for fostering crisis repair in the context of the COVID-19 pandemic and its social consequences and for preparing a green, digital and resilient recovery of the economy (REACT-EU), 23 December 2020.

${ }^{4}$ At this stage the paper will not present any assessment of plans that are in progress; this will appear in a later edition of this series.
} 
with difficult socio-economic and political choices with clear short-term costs for systemic structural changes. In short, returns can be very high but mistakes also very costly.

\section{The economic rationale for Next Generation EU}

The main reason for a coordinated EU-wide recovery plan is that the impact of separate national actions on the single market and single currency area would lose effectiveness. The need for a common fiscal response to an economic crisis has been reiterated by academics for decades, ever since the MacDougal report (CEC, 1977). This view has gained prominence since the 2010 crisis. Based on different models of spillover effects reviewed by Picek (2020) and his own general equilibrium modelling, the introduction of a joint Europe-wide stimulus package has a higher effect than individual uncoordinated interventions, with spillover effects reducing the value of the support for independent non-synchronised actions. Joint actions in member states would generate positive spillover effects across borders, with mutually reinforcing benefits.

The European Central Bank's modelling exercise on the NGEU impacts (ECB, 2021) also presents a positive picture from the implementation of a joint recovery programme at EU level, but warns that the use of recovery as a mere fiscal transfer (i.e. without good programmes and reforms) would not have a sustained positive impact on GDP and just lead to higher debt. The ECB report also makes the point that loans have a lower impact because they add to national debt. Interestingly, it also recommends using RRF loans to replace national debt if there is no capacity to absorb all the loans. The RRF debt should offer lower interest payments and thus improve the economic condition of the country. However, the magnitude of the impacts will depend on the quality of the programmes implemented in the member states.

General equilibrium models are nevertheless based on a number of assumptions about the returns on investment. The impacts will depend on the capacity of member states to absorb and properly use the support, on the functioning of the industrial supply chains, the availability and skills of the labour force, and other enabling factors, many of which are affected by policies (e.g. fiscal or labour market policies). The assumptions used cannot be taken for granted.

It is essential to demonstrate that sharing fiscal capacity in the EU can work and has a purpose that leads to the creation of genuine added value through efficient member state expenditures. The expenditures have to lead to sustainable increases in economic activity that generate returns exceeding the level of liabilities incurred under the recovery programmes. The use of the plural is important here. The Next Generation EU is not big enough to counterbalance government balances sheets that are badly managed or national programmes that are misallocated. If governments do not reform to become more efficient and ensure that any liabilities incurred create added value in the economy, the NGEU investments themselves may be weakened, transforming them into a temporary boost without a long-lasting or multiplier effect. The framework conditions are essential for any investment programme. 


\section{Key risks facing the implementation}

\section{Risk 1. Multiplicity of targets can weaken impact}

Here lies an important level of complexity, the recovery package aims to redirect the economy, not to use the stimulus to just restart the economy based on the existing industrial structure. It aims for a new more digital, cleaner, more circular, more just structure aligned with the climate objectives. This is not what a normal stimulus package usually does, but these are core objectives of the recovery and resilience facility RRF. It is also the reason for the 'resilience' in the name.

A summary of the main requirements based on the regulation and guidelines of the recovery and resilience facility appears below:

\section{a) Requirements}

- to contribute to the seven European Flagships: 1) Power up, 2) Renovate, 3) Recharge and Refuel, 4) Connect, 5) Modernise, 6) Scale-up and 7) Reskill and upskill

- to allocate $37 \%$ of the RFF funding to climate investment based on the methodology for climate tracking

- to dedicate $20 \%$ of the funding to the digital transition based on the methodology for digital tagging

- to contribute to the strategic autonomy of the Union

- to explain how the plans mainstream gender equality and equal opportunities for all

\section{b) Macroeconomic and reform requirements}

- to ensure consistency with the Country Specific Recommendations (CSR) to the member states emerging from the European semester

- to introduce reforms geared to improving conditions for the business sector

- to introduce reforms to improve the quality of public administration

- to adopt more efficient public investment processes, including expanding the effective use of public-private partnerships

- to introduce measures to avoid aggressive tax planning that distorts competition between firms.

\section{c) Overarching new environmental conditions}

- To ensure that the programmes 'do no significant harm' to any of the six environmental objectives as defined in Article 17 of the EU Taxonomy Regulation.

To achieve the objectives above, the potential measures and projects can cover all possible areas, such as promoting business sectors, investing in new sources of energy, supporting biodiversity protection, promoting green farming, investing in digital companies, increasing digital connectivity, addressing social exclusion, reducing the depopulation of marginal regions, promoting innovation, promoting cohesion, connecting marginalised regions, improving gender equality, building social housing, and investing in energy efficiency, coastal protection and so on. 
The lack of focus in some programmes is considerable. The concern is that the measures taken as a response to the 2008 financial crisis had the sole ambition of returning the economy to its pre-crisis level, and the result was muted. A programme with much higher ambitions and a multiplicity of objectives, many of which are related neither to the Covid crisis nor to climate objectives, therefore seems risky. The fact that some of the objectives may clash increases risks.

The biggest concern with such overarching objectives is probably that they require, first and foremost, an extraordinary flexibility and dynamism in the framework conditions, which a number of countries do not have due to their bureaucratic, legal and fiscal structures. The programmes must incorporate serious and deep structural reforms that enable new business models to develop, reach economies of scale and encourage innovative solutions. This even includes accepting a considerable amount of risk.

Another complication comes from the link of the disbursement to the achievement of milestones for which member states need to report progress. This challenge is a tall order, as it is rather difficult to envisage that such ambitious milestone expectations can be achieved in the short period in which the funds need to be disbursed. The milestones can therefore rarely be on results, but rather on process.

On the speed of implementation: for grants, $70 \%$ of the commitments must be submitted by 31 December 2022 and 30\% by 31 December 2023, with demands for loans submitted by 31 December 2023 at the latest. Payments for the measures committed must be completed by 2026 at the latest. ${ }^{5}$ Which milestones will be completed by then? If the objective is to build resilient structures for the future, are those timetables not encouraging the use of funds for faster and less ambitious results? After all, why risk missing a milestone with ambitious targets if something lighter would do?

\section{Risk 2. Sustaining imbalances in the economy through subsidies}

This is the core risk with the NGEU support. The NGEU offers a unique opportunity to reform and restructure the economy while offering support to those affected negatively by the changes. However, it is easier for any government to subsidise existing businesses to avoid the backlash caused by changes in the fabric of certain economic sectors. Large stimulus packages combined with support for ailing companies cover the price signals, which makes potentially solvable companies indistinguishable from those that are not. It is important that the distinction is made sooner rather than later, to help those on the losing side to restructure or close and help the labour force to shift.

Once the crisis subsides, we may indeed face a K-shaped recovery, ${ }^{6}$ which means that the moment the economy opens up, solvable companies will grow in an upward trend, while others will decline. Depending on how the recovery is handled, the implications will be more or less

\footnotetext{
${ }^{5}$ Based on Articles 11 and 12 of Regulation 2021/241establishing the Recovery and Resilience Facility.

${ }^{6}$ A K-shaped recovery occurs when different economic sectors recover at different rates, times, or magnitudes after a recession, or in our case, a pandemic. Market demand may have shifted, or policies may have changed framework conditions for some sectors.
} 
dramatic. This could be the case for expanding online services vs. potentially struggling retail sectors. Will governments address the change needed in struggling businesses that have no sustainable future, or perpetuate their zombie status? This is an important aspect for the recovery package, to focus on changing, not on sustaining activities that are not solvent.

Subsidising companies that were already unsustainable (zombie companies) can brew up an additional crisis. Zombie companies not only generate additional costs for the state, but also accumulate debt which, despite low refinancing costs, could quickly plunge businesses into bankruptcy when support systems cease. The ensuing accumulation of bad debt could lead to defaults and a worsening debt crisis.

In addition, the long-term liquidity expansion and easy financing conditions seem to be pushing investors toward riskier assets with the potential to turn into junk debt (Spinozzi, 2021). Cheap money has also been leading to a rise in the value of financial assets, in contraposition to developments in the real economy. This was a necessary compromise given the urgent need to inject liquidity into the market. But the financial crisis and now the Covid-19 pandemic have exacerbated the gap between asset-poor and asset-rich citizens, as well as regional disparities. This makes it all the more pressing that recovery be applied in such a way as to address these imbalances while developing a more resilient economy.

Recovery therefore needs to include serious reforms and support for companies to close or redirect their activities, as well as sustaining and retraining the workforce. This means introducing an active labour force policy. In fact, this recovery package should do what the recovery actions in the financial crisis did not, i.e. clear the path to reset the economy. While the financial crisis was labelled a lost opportunity, this particular crisis (with partially paralysed sectors of the economy) presents a unique moment of 'suspension' to reset trends. The use of the word 'could' rather than 'can' is because that window of opportunity will not be open indefinitely. Pressure will mount to use the RRF to sustain declining sectors. The role of the recovery and resilience facility, however, is to support the transition to more resilient economic structures. Some funding may indeed be used to cushion the impacts and costs of transition and adaptation to the market after the crisis, but it is not its function to operate as an extended social cushion against the impacts of the pandemic.

\section{Risk 3. Delays in starting the recovery programme}

While a robust and well-programmed recovery is required, it is also important to avoid delays. If the NGEU/RRF are not capable of jumpstarting the EU economy soon, the risk of hysteresis effects in the labour market and the bankruptcies of solvent companies hit by Covid-19 (thus not of zombie companies) will increase. This would deepen both the crisis itself and reduce confidence in the EU's ability to address it. An insufficient policy response at the EU level may lead to a reassessment of financial risks, market volatility and further negative feedback effects. This would further weaken recovery. The European Commission's economic forecasts, corroborated by the analyses presented here, have repeatedly warned of the negative consequences of insufficiently coordinated national policy responses, including the risk of heightened social tensions. The impact of economic uncertainty was felt strongly during the 
difficult negotiations over a stimulus package. Delays can thus damage the stability of the Union. Delays are not necessarily caused by the approval process of the plans but can also emerge during the Own Resources ratification process. If just one of the member state's parliament refuses to ratify, the recovery package will not be able to go ahead.

\section{Risk 4. Lack of European dimension in an integrated economy}

One of the requirements of the RRF is to contribute to the strategic autonomy of the Union, which reflects the conclusions of the New Industrial Strategy of the Commission (2020). However, beyond a mere mention, strategic autonomy is not addressed in the RRF regulations or the guidelines. Something seems to be amiss here, given the importance of transforming the industrial, digital and energy sectors with important objectives in the area of critical value chains. An analysis by Nigohosyan et al. (2021) on the impacts of Covid-19 on European industry identifies the need for a European- level robust value-chains approach to industrial policy. The report identified a lack of policy coherence across member states concerning industrial sectors, including the digital one, which affects efficiency. With the EU now focusing on protecting essential industries and looking towards a circular economy, a joint policy approach in this area would have been welcome.

The original proposal from the European Commission included EU-level instruments for the NGEU, such as the Strategic Investment Facility and the Solvency Support Instrument, which could have played a critical role. The 're-nationalisation' of support by transforming grants and guarantees into loans for the RFF have eliminated a significant EU-level coordination tool. Current RFF plans are all nationally oriented with only an unconvincing request for member states to set up cross-border coordinated activities using the RRF. The draft programmes reviewed do not indicate that this option has been adopted. Even in health, where EU-wide coordination should be enhanced, the draft programmes reviewed do not mention collaboration and possible synergies. The lack of a European dimension means that resilience and the economic impact on the industrial sector will be reduced. Rather than presenting a risk, it seems certain that the result will be suboptimal.

\section{Risk 5. Capacity to run a successful recovery plan}

The ability to successfully set up and run a recovery plan largely depends on the performance and involvement of the managing authorities and intermediary bodies implementing it. While rolling out the funding to sustain incomes is important, the recovery plan should be more than a social policy justified by accompanying projects. If the overall recovery is in fact going to have a lasting effect on the economy, the selection and monitoring of investments needs to be sound and the public administration must be highly proactive towards the private sector to speed up and steer the recovery.

There are two sources of concern. The first relates to the lack of capacity to manage the level of funding and accompanying procedures, and the second to a lack of viable projects that are in line with the RFF twin transition. In the first case, authorities with limited capacity will struggle to properly manage projects; in the second, they may reflect a lack of demand for the 
funds and a potential lack of beneficiaries capable of developing quality projects. In addition, an excessive bureaucratic burden may arise, often a result of combined national and EU requirements. In some countries 'gold-plating' (overloading project approvals with ex ante requirements to avoid problems at the control stage) may simply discourage beneficiaries from applying.

According to the open data provided by the Commission on the Cohesion Policy, some member states seem to have had difficulties absorbing funds during the programming period of the 2014-20 MMF (see Figure 1).Lower absorption rates are not necessarily going to lead to the decommitment of funds or to the inability to use the Next Generation EU funding, ${ }^{7}$ but they indicate that some important measures will need to be taken to facilitate uptake without sacrificing quality. How can speed be enhanced at the same time as improving project quality? Some solutions are discussed in the sections that follow.

Figure 1. Committed and spent funds

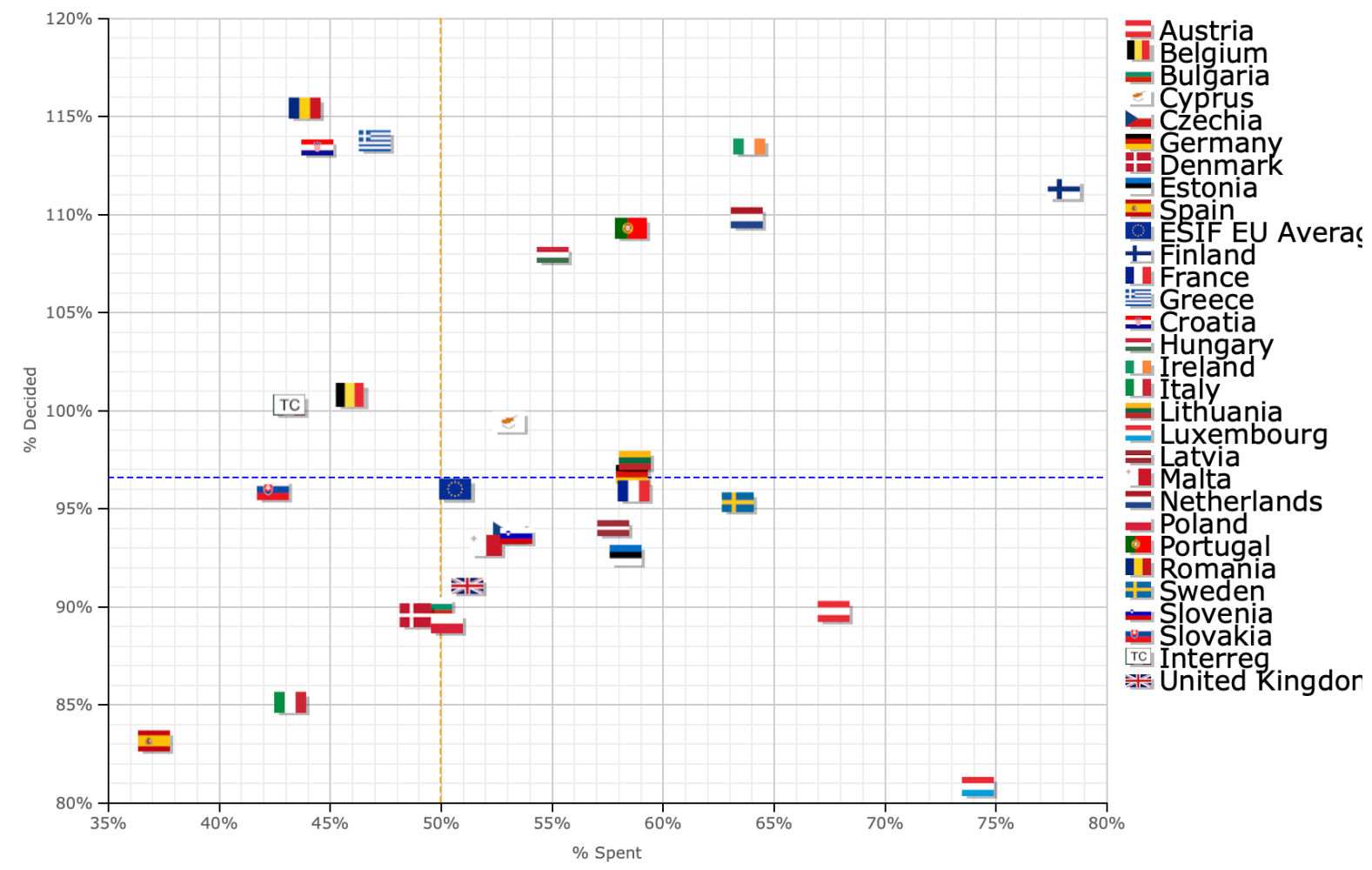

Source: European Commission open data platform for ESI Funds, Period Covered: up to 30/09/2020, https://cohesiondata.ec.europa.eu/overview.

\footnotetext{
${ }^{7}$ The delays depicted in the figure may also be related to the specificities of Cohesion Policy (such as its systems of management and control, which may affect the level of execution of the funds recognised at a particular point in time, or that programming may have taken into account the application of the decommitment rule of $\mathrm{N}+3$, which allows payments until 31 December 2023).
} 


\section{Mitigating the risks to a successful implementation}

\section{Solution 1. National reforms are a pillar to recovery}

The primary tool for a successful recovery and for a more resilient economy is to create the enabling framework. In short, this means reforms, and the more ambitious the change, the larger the reforms needed. It is important to avoid the use of the RRF as an instrument to cover up market and policy failures. These should be addressed through reforms.

In the last two decades the EU has been improving strategic requirements, reporting, monitoring and evaluating procedures and internal financial management systems. There is still work to be done to increase the strategic quality and governance of investments, not only for EU funding, but generally for public funding. Despite the size of NGEU and its RRF, the future development of member states is still overwhelmingly linked to the national management of the economy. Public sector reform and public financial management is an important area of improvement and of growing interest to the IMF (2018) due to the implications on growth. Proper accounting standards and attention to the impact of government actions on the economy need to be improved (Núñez Ferrer and Musmeci, 2019). Trust is one of the most important pillars of the single market, affecting not only intergovernmental relations inside the EU, but also the behaviour of investors.

In addition to financial management, reforms need to include changes to the fiscal system. How the fiscal system is constructed has significant implications on economic activity. What is disincentivised? What is promoted? Taxation matters when the fiscal burden reaches $50 \%$ of GDP, as is the case in many member states. Thus, a combination of high fiscal burden with financial mismanagement can affect economic sustainability.

In the RRF plans, an in-depth analysis of the fiscal structure and regulatory and administrative burden is necessary, pinpointing the effect on the economy and barriers created towards achieving objectives. Plans to remove the barriers and introduce the necessary tax shifts and incentives should be drafted and quickly implemented to support intended changes in the economy. The Country Specific Recommendations (CSRs) provide the basis for reflection and action, and the RRF regulation requires that these form the pillar of the reforms. It is in the area of structural reforms that the disbursement of funds in exchange for the achievement of milestones can be key. The plans should present clear reform commitments that should be reflected in the milestones. The objectives of investments may require some years to fully show their impact, but many improvements in governance and the modernisation of the public sector can be implemented and verified very quickly.

\section{Solution 2. EU reforms to improve implementation effectiveness and speed}

While it is true that some countries have more difficulty than others to fund programmes, there are a number of actions that can be taken to accelerate the funding of projects and improve their efficient implementation. One area of necessary reform has already been debated at length in the High Level Group on simplification established in 2015, which discussed the 
excessive burden and contradictions in the financial control system, with particular attention to auditing procedures (Letáčková, 2016). If the recommendations on single audit and control procedures are followed, some of the present unnecessary burdens could be lifted. An efficient process for checks, controls and an audit trail should be established as recommended by the High Level Group, providing public and private operators with the necessary legal certainty while providing an efficient (one-stop shop) mechanism for the verification of investments and reforms.

Another area of improvement would be a greater focus on results rather than procedures. This becomes more pertinent with the increasing practice of using simplified cost structures linked to delivery targets. The linking of milestones in the RRF to the release of funds requires a strengthened focus on results at the same time. It additionally affects the work of the European Court of Auditors, given that with a results-based system, the focus on procedural error becomes less useful and the calculation of an 'error rate' not always relevant. An increased focus on results requires a strengthening of the ex post mechanisms for evaluation, control, and sanctions. Ensuring that the financial interests of the EU are protected while increasing delivery speed and efficiency requires reforms in this area. This should not only occur at the EU level for EU funds, but should also be pursued by governments establishing transparent, reliable and comparable ex ante and ex post impact evaluations standards, especially for large projects and programmes.

Finally, the role of multilevel governance needs to be reconsidered. To achieve the best results, the recovery programme may require the active participation of local authorities. The RRF is being delivered at national level which may, in a number of actions, reduce rather than increase the desired impact. The plans should identify the best implementing actors in line with the subsidiarity principle. However, care should be taken to ensure that the involvement of regional authorities does not lead to an atomisation of the funding into a many small projects, further diluting the focus on priorities and reducing effectiveness.

\section{Solution 3. Active and useful labour market policies}

Active labour market policies are a key instrument and should be a core element in the plans. The recovery and resilience programmes can only be successful if the labour force can be supported in the transition between sectors and occupations with appropriate up- and reskilling programmes. Education, training and lifelong learning are key to productivity and to building the resilience of both individuals and the economic system. Training systems need to be extended to meet the economic needs of today and tomorrow. Education systems may have to be rethought to prepare the future workforce for a production system that may be more flexible and diverge significantly from the one of the last century.

If parts of the recovery package are released quicker, they should focus on the unemployed and those people under short-time work (STW) schemes, combined with programmes to upgrade skills. This also requires the intervention of the public employment services, as reskilling to help people 'change' employment cannot be expected of employers. In a pandemic this seems a complex task, but this area is key for the recovery in the digital and energy sectors, 
for example. Assuming that economies will largely open up this year due to the vaccination campaign, there is already very little time to put in motion a transformative programme.

\section{Solution 4. Enhancing and improving the use of public private partnerships}

Member states need to mobilise private investment and promote the development of new economic activities. PPPs are one of the areas to expand further, using InvestEU and national promotional banks and setting up collaborative institutions such as specialised funds to address changes in sectors, e.g. for energy or infrastructure. Specialised agencies with public objectives but operating mainly on private sector operations with limited public support could increase trust in areas of change while mobilising the economy. Public-private partnerships and the involvement of public financial institutions can attract investors to develop new activities.

Care must be taken that those partnerships create additional activity and do not displace other private operators, and that benefits are retained. Once the crisis period is over, the role of public institutions should be reviewed, redirected and even downsized, if necessary, to avoid interference and the crowding out of private activity.

Despite the increase in PPPs in the EU from the involvement of EU funding and the EIB, the regulatory framework for PPPs is not comprehensive enough. The successful use of PPPs in some member states has been limited in a number of respects, including a misallocation of risks between the public and private sector. A better unified PPP framework from the European Commission could be useful - maybe even a directive providing some clear framework, as PPPs have not been harmonised, and no legislative instruments for regulation currently exist, unlike for procurement and concessions (Bogdanowicz, 2020).

\section{Conclusions}

A key message is to focus on how to handle the likely incoming K-shaped recovery. To overcome the economic, social and environmental challenges, it is crucial to build a recovery and resilience response that promotes the transformations our societies and economies need.

This paper has highlighted a number of risks that could weaken the impact of the Recovery and Resilience plans.

The wide range of objectives and eligible measures could lead to ineffective programmes that are unable to generate the kind of returns necessary to ensure economic sustainability and achieve social and environmental goals. Member states also face the contradictory challenge of having to present ambitious programmes while simultaneously having to achieve quick results to reach milestones and access support. This could induce governments to limit the scope of some programmes to be eligible but will result in lacklustre actions.

There is a growing consensus that the economic restart after the pandemic will lead to a Kshaped recovery, where some businesses are able to renegotiate their position in the economy positively but others may face insolvency and collapse. The high indebtedness generated by 
the crisis may hit the economy too. Any delays to the start of the recovery and resilience facility may also exacerbate this risk.

The national focus of the plans is missing the EU elements to reinforce the single market and the critical value chains. Plans are unlikely to reflect the highly complex value chains across the EU, which are essential to addressing the EU's industrial strategy objectives.

The capacity to both create the right programmes in a short period of time and implement them well is in question. Some member states may face either administrative capacity limits or simply not be able to find projects capable of generating sufficient value.

While highlighting these risks, this report presents a number of solutions. Most are in the hands of member states which should, in their own long-term interests, introduce considerable reforms to their public administrations, labour market laws and programmes, and fiscal systems. For maximum impact, the right framework conditions are an essential pillar of RRF support.

A number of other reforms would be important, also at the EU level. First, moving forward with simplifying procedures without reducing efficiency (even enhancing it), starting with the introduction of a single audit system. Furthermore, the mechanisms to improve the mid-term and ex post control, evaluation and also sanctions should be reinforced, reducing the focus on procedures while ensuring higher impact.

Active labour market policies that prepare member states for more digital, flexible economies are necessary. Current economic trends in terms of skill requirements and work practices must be reflected and member states should not maintain structures that are misaligned.

Finally, while PPPs are increasing in importance, they are not a panacea and require an improved framework. There are no harmonised EU rules for PPPs, which can lead to a suboptimal risk distribution between the public and private sector (e.g. placing excessive risk on the public sector). There should be a legal framework in place, as there is for public procurement and concessions. 


\section{References}

Bogdanowicz P. (2020), "Regulation of PPP and concessions in European Union law - different but equal?", in P. Bogdanowicz, R. Caranta and P. Telles (eds), Public-Private Partnerships and Concessions in the EU - An Unfinished Legislative Framework, European Procurement Law series, Elgar Online, pp. 1-16 (www.elgaronline.com/view/edcoll/9781839105005/ 9781839105005.00007.xml).

Commission of the European Communities (1977), "The MacDougall Report", Study group on the role of public finance in European integration, Volume I, Brussels, April.

European Commission (2020), "Communication from the Commission - A new industrial strategy for Europe", $\operatorname{COM(2020)} 102$ final.

ECB (2021), "The macroeconomic impact of the Next Generation EU instrument on the euro area", Occasional Paper Series, No 255, January (www.ecb.europa.eu/pub/pdf/scpops/ ecb.op255 9391447a99.en.pdf).

IMF (2018), "Managing public Wealth", Fiscal Monitor Report, October (www.imf.org/en/ Publications/FM/Issues/2018/10/04/fiscal-monitor-october-2018).

Letáčková, O. (2016), "High Level Group of Independent Experts on Monitoring Simplification for Beneficiaries of the European Structural and Investment Funds: Report on 'Evidence on cross-cutting audit issues", European Commission, 29 November (https://ec.europa.eu/ futurium/en/system/files/ged/29.11.16 hlg audit olga letackova 0.pdf).

Núñez Ferrer J. and R. Musmeci (2019), "Beyond Public Debt and Deficits - The Hidden Rapid Erosion of Government Balance Sheets is a Financial Threat to Society", CEPS Research Report, No. 2019/10, March (www.ceps.eu/ceps-events/beyond-debt-and-deficits-thehidden-rapid-erosion-of-eu-government-balance-sheets-is-a-financial-threat-to-societyhow-to-stop-it/).

Picek (2020), "Spillover Effects from Next Generation EU", Intereconomics, Vol. 55, No. 5, pp. 325-331 (www.intereconomics.eu/contents/year/2020/number/5/article/spillovereffects-from-next-generation-eu.html).

Spinozzi A. (2021), "A successful Covid-19 vaccine kills companies", in Saxo Bank's 2021 Outrageous Predictions, Saxo Bank (www.home.saxo/content/articles/outrageouspredictions/a-successful-covid-19-vaccine-kills-companies-08122020).

Van Vet, M., D. Nigohosyan, J. Núñez Ferrer, A. K. Gross, S. Kuehl, M. Flickenschild, "Impacts of the COVID-19 pandemic on EU industries", Report for the European Parliament's ITRE Committee, forthcoming. 


\section{Annex 1. Members of the Recovery and Resilience Reflection Group}

$\begin{array}{ll}\text { Peter Blizkovski } & \text { Secretary General - Committee of the Regions } \\ \text { Alessandro Carano } & \text { European Commission -Recovery and Resilience Task Force } \\ \text { Alfredo de Feo } & \text { Professor, European University Institute } \\ \text { Carlo Altomonte } & \text { Professor, University of Bocconi } \\ \text { Theo Jens } & \text { Professor, University of Hasselt } \\ \text { Carmen Jordán Asensi } & \text { Counsellor, Economic Affairs - Cabinet of the Spanish } \\ & \text { Presidency } \\ \text { Ivailo Kalfin } & \text { Senior Lecturer, University of Varna, Former foreign and } \\ \text { José Moises Martin } & \text { labour minister and MEP, Bulgaria } \\ \text { Marta Pilati } & \text { Economist, Agenda Publica } \\ \text { Eulalia Rubio Sander } & \text { Policy Analyst, European Policy Centre } \\ \text { Van de Laar } & \text { Senior Research Fellow, Jacques Delors Institute } \\ \text { Fien Verheij } & \text { Jurist, Dutch Central Bank }\end{array}$

